\section{PREHISTORIC METALLURGY OF IRON}

\author{
Notes on Prehistoric and Early Iron in the Old \\ World
}

By H. H. Coghlan. (Occasional Papers on Technology, No. 8.) Pp. $220+16$ plates. (Oxford : Pitt Rivers Museum, The University, 1956.) 258.

TN 1951 the Pitt Rivers Museum published as 1 Occasional Paper on Technology, No. 4, "Notes on the Prehistoric Metallurgy of Copper and Bronze in the Old World", by H. H. Coghlan (see Nature, 168, $531 ; 1951$ ). This is now followed by Occasional Paper No. 8; which deals with prehistoric and early iron in the Old World, by the same author. Taken together, these represent what is clearly one of the most substantial contributions yet made to our knowledge of the metallurgical technologies in prehistoric times. Prepared by an engineer, they possess a degree of reality which has not always been present in publications in this branch of knowledge.

It is the second of these, dealing with iron, with which we are here concerned. After a discussion of the nature, properties and uses of meteoric iron, in which a large amount of material is collected and various opinions discussed and correlated so far as this is possible, it emerges that there is still muich to learn, and in that process the trained metallographer must play a definitely more important part than has hitherto been allotted to him. As an example, the reader of the present publication might well never realize that the curious twin bands known as 'Neumann lamellæ', which were first discovered in meteorites and which are well recognized in such materials, occur also in synthetic iron and are not, therefore, conclusive evidence of meteoric origin. The early smelting processes which led to a sponge of soft, pure iron are discussed in relation to the types of ore available and the slags which were produced. This stage of the metallurgy is moderately clear. Molten iron could never have been produced at the temperatures which were available, and the 'steel' must clearly have been the result of carburization of such pure iron by a process which, in its essentials, differed little if at all from the production of 'blister' steel, which has become obsolete only within living memory. Damascene steel and the shear steel carving knives of our fathers were the result of the careful and repeated heatings and forgings of such cemented iron. Whether or not cast iron, that is, high-carbon material with a melting point sufficiently low for it to be poured into a mould, was produced until comparatively late times, has perhaps not finally been settled, but there can be little doubt that as a routine product it is a material which played no essential part in the metallurgy of at any rate pre-Roman times. It must not be forgotten, however, that the melting point of a white cast iron containing perhaps 4 per cent of carbon, around $1,150^{\circ} \mathrm{C}$., is not so very much higher than that required to melt copper, and that accidental overheating during the carburization process may, on occasion, have led to its production.

One most curious fact which the author develops is that after its first utilization towards the end of the early Bronze Age, iron appears to have suffered an almost total eclipse, to re-emerge in the late
Bronze Age. The earliest use of iron, when it must have been a material of considerable scarcity and when, as is not impossible, the major portion of the available supplies was meteoric, was limited in the main to small artistic or religious objects. Early iron, soft, and more or less unreliable mechanically, could have been no very serious competitor to the rapidly developing bronze alloys. As the meteoric supplies were used up, therefore, there would be comparatively little incentive for the production of what must at the time have been both an inferior material and one much more difficult to produce than bronze. With advances in technical knowledge and in particular with increasing appreciation of the improvements to be effected by carburizing the iron and converting it into steel, competition with bronze entered on a new phase, and this in the main explains its reappearance.

One of the difficulties in elucidating the full story of the early history of iron arises from the fact that the design of the furnaces in which the metal was produced is far from adequately known. As a result of weathering and deliberate destruction, the upper part of such furnaces has frequently dis. appeared, while further, the examination of what is left has rarely been carried out by those with adequate technological knowledge. Despite this, certain general outlines have emerged. Starting with what were little more than holes in the ground, domeshaped furnaces were developed with an aperture at the top for the escape of the products of combustion and reaction, and with one or more openings at the base through which a blast of air, natural or artificial, could be directed and the semi-solid product of the operation removed. Here consistent lines of development appear to have been followed from the earliest days to the furnaces of the late Middle Ages which bear a recognizable similarity to the relatively gigantic structures with which the modern metallurgist is concerned. The tools of the smith and his technical art are described in detail and with skill, and many readers will be surprised at the quite astonishingly modern appearance of the tongs, anvils, etc., used by the very early worker.

It is possible, however, that the part of the report which will prove of the greatest permanent value consists in the appendix by Mr. P. Whitaker, manager of metallurgical research of Messrs. Stewarts and Lloyds, Ltd., on some sixteen samples of early iron, varying in age from the late eighth century B.c. to about A.D. 900. These samples have been photographed, analysed and examined micrographically with very great care and skill, as a result of which it has proved possible to describe the techniques of production both of the original material and of the particular article examined with a high degree of accuracy and detail.

Taking the two reports together, all those concerned with the early history of the ferrous and the non-ferrous metals owe a debt of gratitude to the author, the Museum and all those who have been associated in any way in their preparation. There are points with which the metallurgist and metallographer will hesitate to agree, but these are not matters of great substance, and do not affect the general picture which has been painted. There is left the vivid impression of a body of men who, over much more than a millennium, were investigating natural phenomena of importance to their communities and were, in fact, the research workers of their time.
F. C. ThоMPSON 